\section{Commentary: Obesity in the time of coronavirus disease 2019 (COVID-19)}

\author{
Ashish S. Shah, MD
}

While obesity remains an enduring part of modern health care, the biology and physiology appear to be surprising and varied. Obesity and its paradoxes are the subject of serious research. Among those with obesity, the coronavirus disease 2019 (COVID-19) pandemic has also seen a worrisome susceptibility to severe respiratory failure. However, for the surgeon, obesity is universally a physical challenge and almost all postoperative considerations revolve around the mechanical needs of these patients. The lessons learned from bariatric surgery may be relevant but are difficult to implement broadly. The hospital challenges to staff, both in and out of the operating room, are important and exhausting. A subset of young patients with obesity and severe acute respiratory syndrome coronavirus 2-COVID-19 infection drive critical care teams to consider extracorporeal life support (ECLS) and the difficult implications of such a decision. The current review summarizes these challenges and touches upon some physiologic features of obesity relevant to ECLS. ${ }^{1}$ The authors offer a sensible approach to ECLS in those with obesity and some practical considerations with respect to cannulation and circuit configurations. The review introduces the cardiothoracic community to the technique of esophageal pressure measurements. This may better reflect intrathoracic pressure and in turn optimize ventilator settings. Early in the realworld global experience with ECLS, the patient with

From the Department of Cardiac Surgery, Vanderbilt University Medical Center, Vanderbilt Medical Center East, Nashville, Tenn.

Disclosures: The author reported no conflicts of interest.

The Journal policy requires editors and reviewers to disclose conflicts of interest and to decline handling or reviewing manuscripts for which they may have a conflict of interest. The editors and reviewers of this article have no conflicts of interest.

Received for publication Sept 6, 2021; revisions received Sept 6, 2021; accepted for publication Sept 10, 2021; available ahead of print Sept 16, 2021.

Address for reprints: Ashish S. Shah, MD, Department of Cardiac Surgery, Vanderbilt University Medical Center, Vanderbilt Medical Center East, 1215 21st Ave South, Suite 5025, Nashville, TN 37232 (E-mail: ashish.s.shah@vanderbilt.edu).

JTCVS Techniques 2021;10:350-1

2666-2507

Copyright (c) 2021 The Authors. Published by Elsevier Inc. on behalf of The American Association for Thoracic Surgery. This is an open access article under the CC BY-NCND license (http://creativecommons.org/licenses/by-nc-nd/4.0/).

https://doi.org/10.1016/j.xjtc.2021.09.022

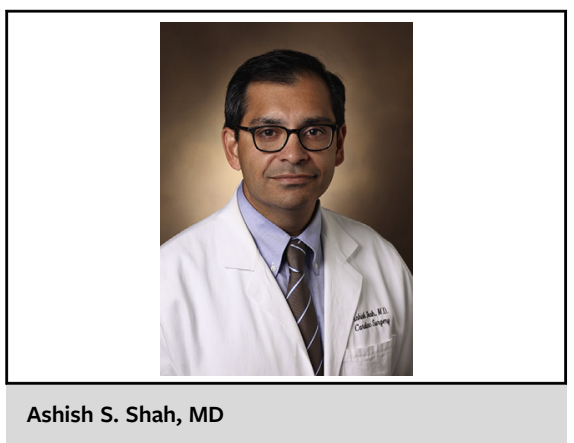

CENTRAL MESSAGE

Obesity and extracorporeal support demand a unique approach and focus on the immunobiology of associated lung failure.

obesity (as defined by body mass index) was excluded from consideration. However, as the pandemic progressed and the burden of severe disease shifted from the elderly to younger and bigger patients, many teams felt compelled to offer advanced therapies. While implementing ECLS in patients with obesity has some significant challenges, it's the management and physiologic goals that are the real issues. What are the true parameters of support: flow, oxygen delivery, venous saturation, blood pressure? What is the optimal ECLS configuration to allow for rehabilitation? How do teams reconcile the malnourished patient with obesity and sarcopenia? It is likely that the biologic susceptibility of patients with obesity to severe acute respiratory syndrome coronavirus 2-COVID-19 lung disease will also impact ECLS management and outcomes. How will patients with obesity with comorbid conditions respond to the modern mRNA-based vaccines? Perhaps the more difficult question is should we even offer ECLS? Our own highly selected experience at Vanderbilt suggests that early outcomes are similar in COVID-19 but with scarce resources is similar good enough and sustainable? Long-term outcomes are unknown and, more importantly, what level of permanent disability will we see for the survivors?

The present review touches on many important challenges for patient with obesity on ECLS. Many of these principles, optimal support configuration and infrastructure for earlier mobilization, will be relevant in the postCOVID-19 period. Similarly, insights from these experiences on the biology of obesity will certainly benefit 
cardiothoracic surgical teams as they increasingly care for these patients. Life in the time of COVID-19 will pass, but the era of obesity will not.

\section{Reference}

1. Javidfar J, Zaaqoq AM, Yamashita MH, Eschun G, Jacobs JP, Heinsar S, et al. Venovenous extracorporeal membrane oxygenation in obese patients. J Thorac Cardiovasc Surg Tech. 2021;10:335-48. 